\title{
Safety Distance Determination for 500 kV AC Transmission Line's Helicopter Inspection
}

\author{
Shuwei Wan, Xingming Bian, Lan Chen, Liming Wang, Zhicheng Guan \\ Graduate School at Shenzhen, Tsinghua University, Beijing, China \\ Email:wansw07@foxmail.com
}

Received February, 2013

\begin{abstract}
As an efficient and advanced line inspection method, helicopter line patrol is gradually more and more used in transmission lines inspection, promoting the elaborate operation of transmission lines and reducing the management cost. However, as a 'floating-potential conductor' near to a high-voltage transmission line, the helicopter would be at a high electric field region; and bring security risk to equipment and operating personnel. In this paper, the electric field strength near the cabin at locations of different distance from transmission lines is investigated by calculation, and the field in the helicopter cabin is also calculated with finite element method (FEM). The result indicates that the potential difference becomes higher with the decrease of the distance between the helicopter and transmission line. Considering the discharge energy and the guarantee of the persons' safety, the safety distance is determined as $d \geqslant 15 \mathrm{~m}$.
\end{abstract}

Keywords: Transmission Lines; Electric Field; Helicopter Inspection; Safety Distance; Limit-value; Transient Electric Shock

\section{Introduction}

Power transmission lines are a key part of the power system and are exposed all the year round to the prevailing weather conditions. It follows that they are more prone to faults than other parts of the system. As an efficient and advanced line inspection method, helicopter line patrol is used in inspection of transmission line gradually, promoting the elaborate operation and management. Helicopter has the ability to ascend and descend vertically and to hover motionless at any height, making them ideally suited for monitoring overhead transmission lines [1-5]. Helicopter enables close observation of the conductors, insulators, fittings and towers, while with infrared and UV inspection systems, operators can clearly see where corona and other discharges are occurring [6-10].

However, when a helicopter is close to a transmission line, it will, as an isolated conductor, cause a distortion of the electric field distribution. This will be particularly important around those parts of the helicopter having a small radius of curvature where the field will be high, perhaps causing localized discharges and the possibility of a breakdown between line, helicopter and ground, with the consequent dangers to helicopter, personnel and equipment.

Calculations concerning floating conductors have been considered by several investigators [11-16]: Tadashi used a charge simulation method to determine the field near a floating conductor touching two dielectric media [11]; Lucian employed a boundary-element method to determine the field in the region between a charged body and a conducting disc at a floating potential [12]. Yu discussed the effects of a floating-potential conductor, near to a transmission line; the electric field was studied both by experiment and finite-element computation. An isolated metal sphere and a model of a helicopter were used as the floating-potential conductors and were placed near the overhead transmission line [13].

Several authors have considered the fields near or below 3-phase and DC transmission lines with reference to sag and ground characteristics. Many researchers used 2D-model to calculate the field distribution near transmission lines [17-19], i.e. sag, span and pylons are neglected. The error of result is large. Trlep analyzed a case more realistic than the ideal case that assumes a flat surface under transmission lines. The result reveals a strong impact of the configuration of the ground surface and the presence of conducting bodies under transmission lines on the electric field distribution [18]. Some researchers used 3D-model to analyze it [20-23]. Dein took the influence of tower height, sag, span and the angle of two spans into consideration [20], calculating the earth's surface field distribution below $500 \mathrm{kV}$ transmission lines. The maximum field strength is about $10 \mathrm{kV} / \mathrm{m}$, and the main component is perpendicular to the surface. Hameyer used semi-numerical method and finite-element method 
(FEM) to calculate the field. The result of $157 \mathrm{kV}$ transmission lines shows that the maximum field strength (1m above the ground level) is about $0.5 \mathrm{kV} / \mathrm{m}$ [21]. Zhang discussed the effect of altitude height to $500 \mathrm{kV}-\mathrm{HVDC}$ with calculation and analog experiment. Under the same conditions, the surface field under DC transmission lines increases as the altitude height rises, and the rising rate is $2 \sim 4 \mathrm{kV} / \mathrm{m}$ per $1 \mathrm{~km}$ [22]. Amiri used finite-element method (FEM) and charge simulation method (CSM) to discuss the effect of sag on field distribution under $500 \mathrm{kV}$ transmission lines. The maximum surface field strength is about $8.5 \mathrm{kV} / \mathrm{m}$ at mid-span while it is about $5 \mathrm{kV} / \mathrm{m}$ near the pylon [23].

At present, the safety distance of $500 \mathrm{kV}$ transmission lines helicopter line patrol is mainly estimated by experience. It is twice the length of helicopter wing plus power operations safety distance. According to the estimation, the distance from helicopter to lines - both horizontal direction and vertical direction - should be over $20 \mathrm{~m}$ [24], and it should be over $25 \mathrm{~m}$ while helicopter is hovering motionlessly near pylon [25].

As the helicopter flies close to power line, transient electric shock phenomena might occur, resulting in the uncomfortable feeling generated by the persons in the helicopter. Therefore, the clarification of transient electric shock is of obvious significance to power corporation, and also it has been gradually becoming an interesting object of research work by both physicists and electrical engineers [26-28]. However, most of the early researchers carried out the investigation about transient electric field on the ground or underwater, none of them noticed or studied such phenomenon in the helicopter. The effect of small helicopter model on the electric field near overhead transmission lines was studied in our previous work [13].

Many researchers have considered the field distribution near or below transmission lines, but none appear to have considered the field distortion due to helicopter near the transmission lines. In this paper the effect on the electric field around helicopter near to transmission lines is considered by numerical calculation. The transient electric shock was analyzed, and then, the safety distance of helicopter inspection was suggested.

\section{Numerical Calculation}

The main material of pylon is angle iron. Because the ratio of maximum and minimum component size is large; it is hard to finite-element meshing. Taking the network structure of pylon into account (Figure 1(a)), and ignoring the inner field distribution, the pylon is modeled as a solid tower in the model used for the computation, as shown in Figure 1(b).

The 3D electric field calculation model and the dimensions of BELL206 helicopter are present in Figures 2(a) and (b). There are two persons in the cabin while inspection, which is shown in Figure 2(c). The sectional plane of the model in the helicopter cabin is shown in Figure 2(d). As shown in Figure 2(c), it is clear that the cabin is not a pure Faraday cage because of the windows; therefore the electric field will certainly exist in the cabin. The line's voltage is symmetrical three-phase and the lineto-line voltage is $500 \mathrm{kV}$ (Effective value).

\section{Results for Field Calculation and Experiment}

As the mid-span of transmission lines is the closest part to the ground, the field strength is larger than other places. The electric field at mid-span along the horizontal line or $45^{\circ}$-line (As shown in Figure 3) normal to the bundled conductor and linking the conductor and the helicopter was calculated and measured.
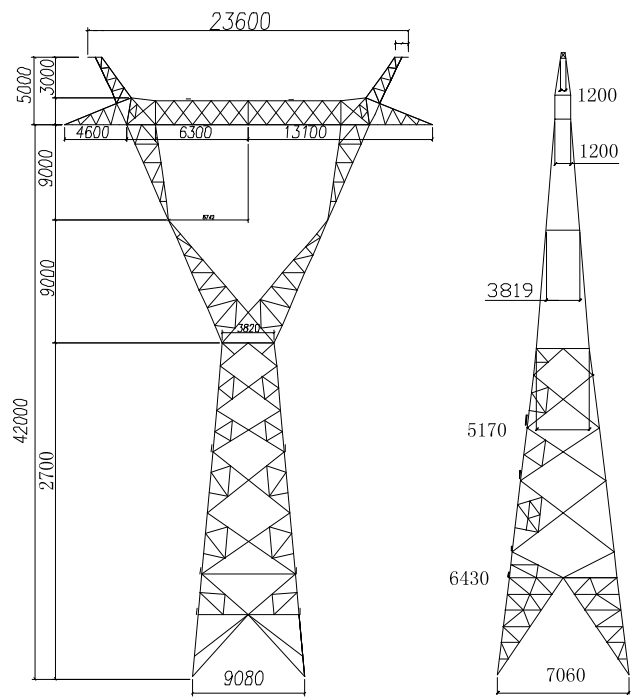

(a) The parameter of $500 \mathrm{kV}$ pylon

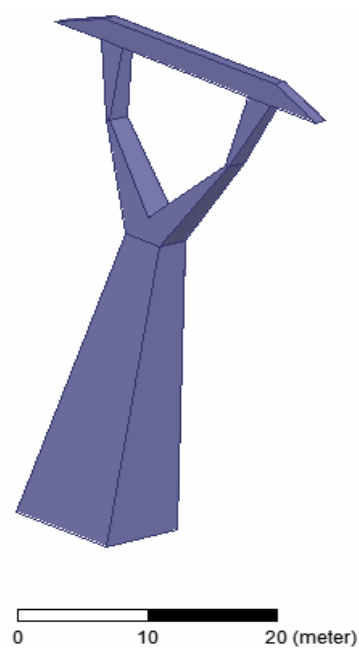

(b) FEM computing model

Figure 1.500 kV pylon. 


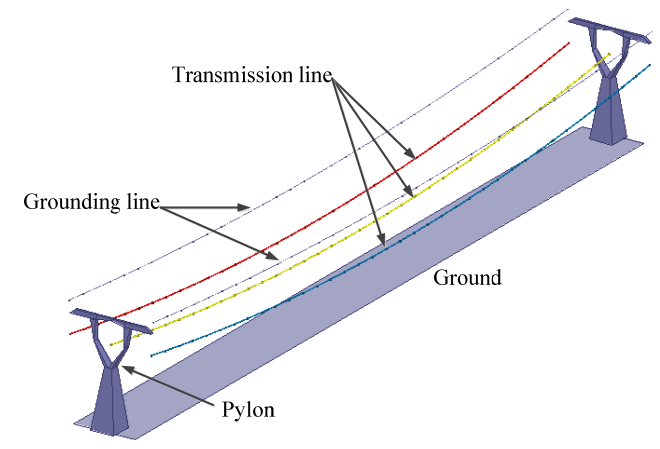

(a) 3D Calculation model

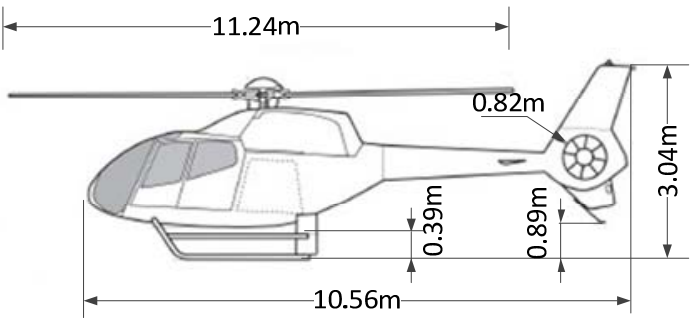

(b) The dimensions of helicopter BELL206

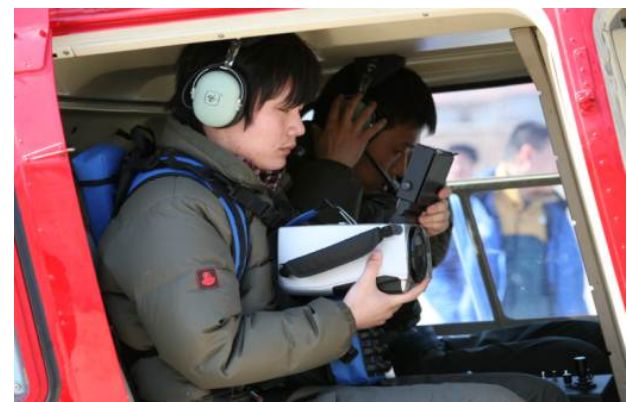

(c) Diagram While Inspecting (Did not take off)

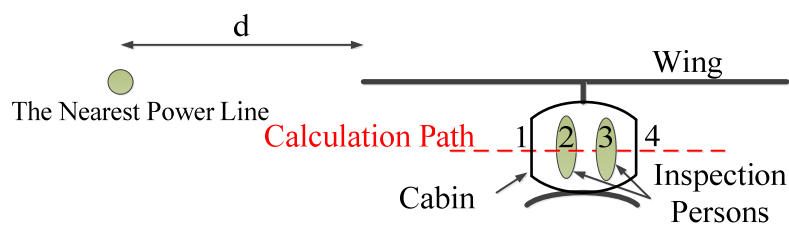

(d) Diagram of Calculation Model in Cabin

Figure 2. Calculation Model.

The calculated and measured results are as shown in Figure 4 for horizontal line and $45^{\circ}$-line, the agreement is good.

Consideration of Figure 4 shows that the calculated field values are consistently higher than the experimental ones by some $15 \%$. The greater discrepancies are perhaps because any small positioning errors of the helicopter and meter up or down, or sideways, or away from the transmission lines, especially the positioning errors of helicopter, will cause a decrease in the measured field. Possibly the effect of the finite size of the metal parts of the electric field meter itself may lower the reading in a non-linear and rapidly-changing field.

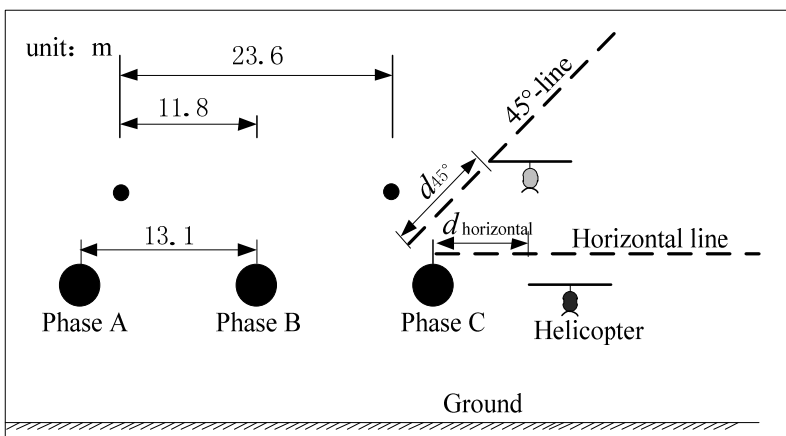

Figure 3. The diagram of helicopter at different location from transmission lines.

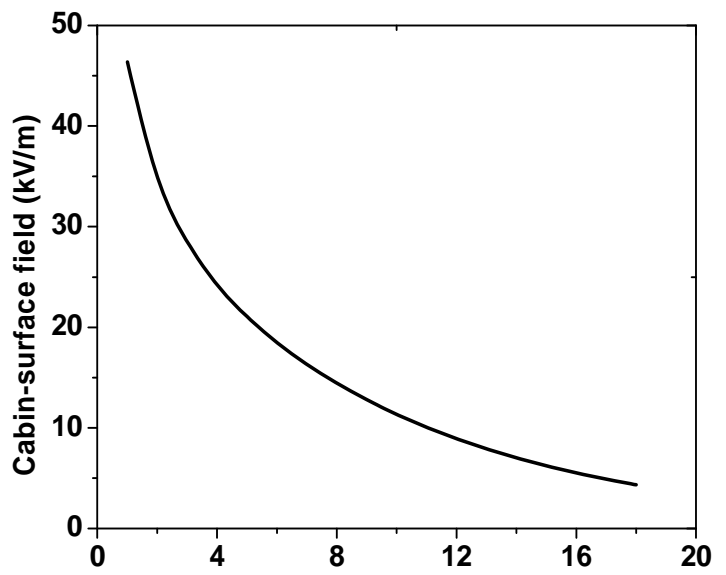

Distance from helicopterto the nearest transmission line $(\mathrm{m})$

(a) Cabin-surface field while helicopter is at different location along horizontal line at mid-span

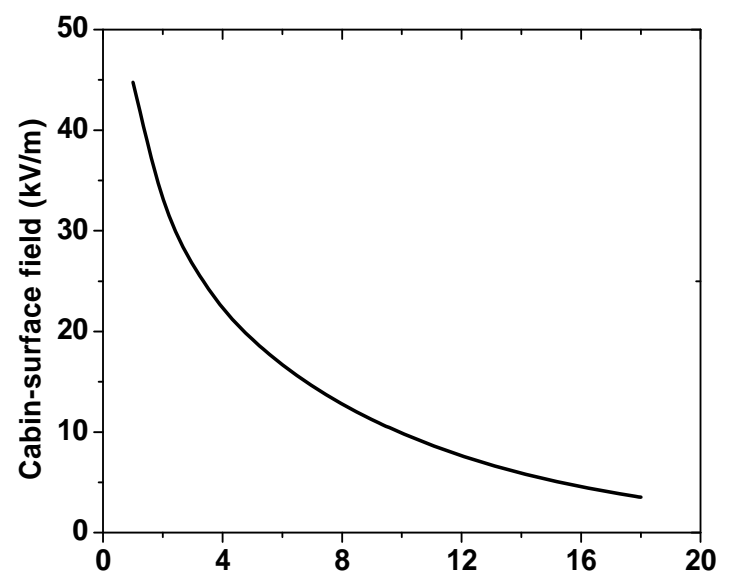

Distance from helicopterto the nearest transmission line $(\mathrm{m})$

(b) Cabin-surface field while helicopter is at different location along $45^{\circ}$-line at mid-span

Figure 4. The cabin-surface electric field of helicopter at mid-span.

Through the result in Figure 4, the filed near helicopter is small and the persons is safe, while the distance from helicopter to line is over $10 \mathrm{~m}$. 


\section{Analysis for Transient Electric Shock}

When the distance between the helicopter and transmission line (d) is in the range $4 \mathrm{~m}$ to $20 \mathrm{~m}$, the potential and electric field around the helicopter cabin is calculated by finite element method, the results ( $d=4 \mathrm{~m}, 10 \mathrm{~m}$ and $20 \mathrm{~m}$ ) are present in Figure 5. Case $\mathrm{d}=10 \mathrm{~m}$ is taken as an example to explain the results.

As shown in Figure 5(a), the potential at middle cabin changes slightly. The electric field near the cabin window is not shielded by the helicopter airframe, but decreases very fast at the middle cabin. The persons' potential $\left(U_{2}, U_{3}\right)$ induced is $103.53 \mathrm{kV}$ and $103.11 \mathrm{kV}$ respectively. The maximum potential difference between the person and helicopter is $1.4 \mathrm{kV}\left(U_{12}\right)$.

The case of the helicopter at different positions is also calculated and the results are displayed in Figure 6.

Transient electric shock is mainly determined by the discharge energy between two objects, which largely depends on the capacitance of the objects and the potential difference between them. It is $50 \sim 400 \mathrm{pF}$ while the person is standing and $400 \sim 800 \mathrm{pF}$ while the person is sitting [29]. The capacitance between the helicopter and person (sitting) was tested for at least 50 times, and it

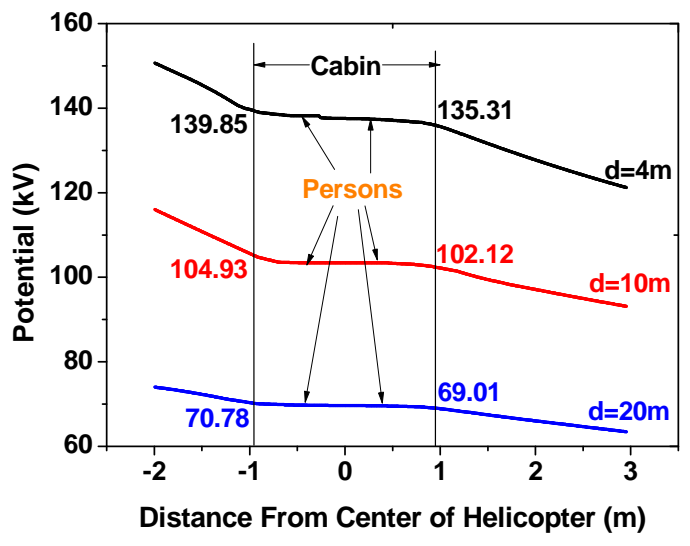

(a) Potential distribution along the calculation path

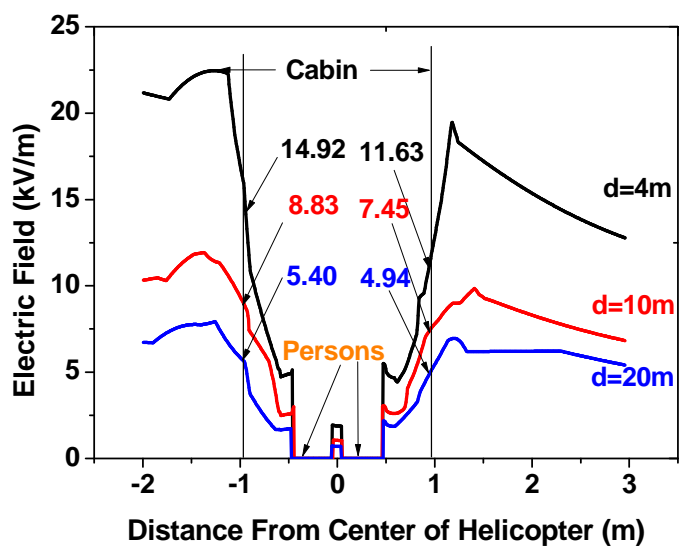

(b) Electric field distribution along the calculation path

Figure 5. Calculation result of $d=4 \mathrm{~m}, 10 \mathrm{~m}$ and $20 \mathrm{~m}$.

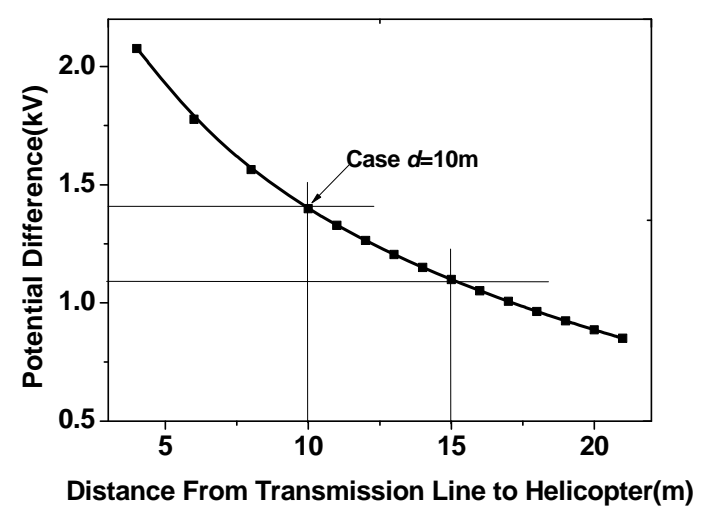

Figure 6. Potential difference of the helicopter at different positions.

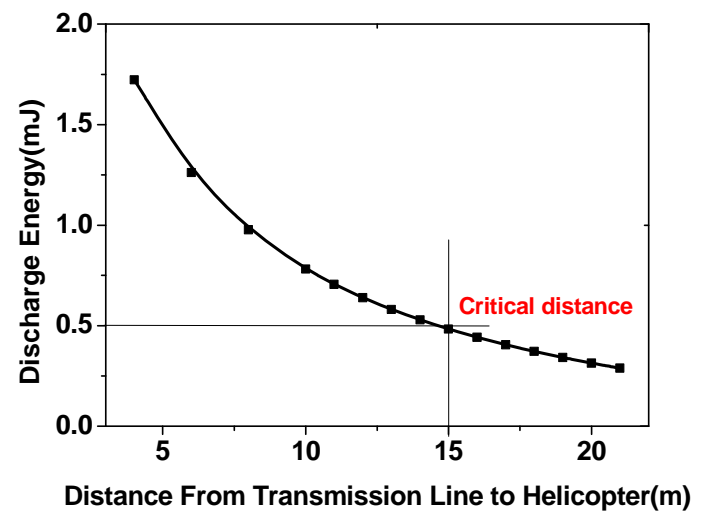

Fiugre 7. Discharge energy between personnel and airframe.

was in the range $400 \mathrm{pF}$ to $800 \mathrm{pF}$. In order to ensure the inspection personnel's persons safety, the severest condition is taken into consideration. Therefore, the capacitance between person and helicopter airframe is set as $800 \mathrm{pF}$, then the discharge energy is acquired (Once the inspection person touches the helicopter airframe), the result is present in Figure 7.

While the discharge energy is over $0.5 \mathrm{~mJ}$, the person would feel uncomfortable [29], so the critical discharge energy is set as $0.5 \mathrm{~mJ}$. The safety distance could be determined as $d \geqslant 15 \mathrm{~m}$ through the curve in Figure 7. According to this suggestion, transient electric shock has not happened to the persons in the helicopter during their inspection anymore. Consequently, this analysis is of great significance to the helicopter inspection in power grid.

\section{Conclusions}

The surface electric field of helicopter was studied both by experiment and finite-element computation near to transmission lines. And the filed near helicopter is small and the persons is safe, while the distance from helicopter to line is over $15 \mathrm{~m}$. Transient electric shock exits 
while helicopter is in a high field region, and it is harmful to inspection persons. The electric field near the cabin window is not completely shielded by the helicopter airframe, but decreases very fast at the middle cabin. Through the critical discharge energy for person, the safety distance is determined as $\mathrm{d} \geqslant 15 \mathrm{~m}$, and it has been well adopted in power grid already.

\section{Acknowledgements}

The authors acknowledge financial support from the key Project of National Basic Research Program of China (2009CB724503)

\section{REFERENCES}

[1] L. M. Alexander and O. K, Mangum, "Economics of Transmission-line Maintenance and Repair by Helicopter," Transactions AIEE on Power Apparatus and Systems, Part III., Vol. 72, 1953, pp. 1044-1050.

[2] J. Toth and A. Gilpin-Jackson, "Smart View for a Smart Grid Unmanned Aerial Vehicles for Transmission Line,” Proceedings of 1st International Conference on Applied Robotics for the Power Industry, Vancouver, BC, Canada,2010, pp.1-6.

[3] J. W. Smith, G. Gela and M. F. McGranaghan, "Control of Line-to-line Overvoltages for Helicopter-based Live Work on a 500kV Transmission Line," 2008 IEEE Power and Energy Society General Meeting - Conversion and Delivery of Electrical Energy in the 21st Century, Pittsburgh, PA, US, 2008, pp.1-7.

[4] IEEE ESMOL Subcommittee, "Recommended Practices for Using a Helicopter in a Wire Environment," IEEE 11th International Conference on Transmission \& Distribution Construction, Operation and Live-Line Maintenance, Albuquerque, NM, USA, pp.1-7, 2006.

[5] E. L. Harris, B. D. Rindall, N. J. Tarko and O. C. Norris-Elye, "The Effect of a Helicopter on dc Fields and Ions,” IEEE Transaction on Power Delivery, Vol. 8, 1993, pp. 1837-1841. doi:10.1109/61.248292

[6] C. Y. Zang, H. S. Ye and H. C. Lei, "Using Ultraviolet Imaging Method to Detect the External Insulation Faults of Electric Device,” IEEE Conference on Electrical Insulation and Dielectric Phenomena, Wuhan, China, 2009, pp. 26-30.

[7] H. Ha, S. Han and J. Lee, "Fault Detection on Transmission Lines Using a Microphone Array and an Infrared Thermal Imaging Camera," IEEE Transactions on Instrumentation and Measurement, Vol. PP, 2011, pp. 1-9.

[8] C. Y. Zang, J. J. He and X. G. Yin, "Status and Application Foreground of Ultraviolet Technology on Fault Detection of Power Devices," International Conference on Condition Monitoring and Diagnosis, 2008, pp. 122-125.

[9] G. Jaensch, H. Hoffmann and A. Markees, "Locating Defects in High Voltage Transmission Lines," Proceedings of IEEE 8th International Conference on Transmis- sion \& Distribution Construction, Operation \& Live-Line Maintenance, Orlando, FL, USA, 1998, pp. 179-186.

[10] L. Du, T. Cui and C.X. Sun, "Detecting AC Corona DisCharges with the UVTRONR2862-Type Ultraviolet Sensor,” High Voltage Engineering, Vol. 35, 2009, pp. 272-276.

[11] Tadasu, Takuma and K. Tadashi, "Numerical Calculation of Electric Fields with a Floating Conductor," IEEE Transactions on Dielectrics and Electrical Insulation, Vol. 4, 1997, pp. 177-181. doi:10.1109/94.595244

[12] L. Dascalescu, P. Ribardiere and J. Paillot, "Computational Estimation of ESD Conditions between a Charged Body and a Conductor of Floating Potential," IEEE Transactions on Industry Applications, Vol. 37,2001, pp. 759-765. doi:10.1109/28.924756

[13] D. Yu, S. Wan, F. Chen, et al., "The Effect of Foating-potential Conductors on the Electric Feld near OverHead Transmission Lines,” Journal of Electrostatics, Vol. 70, No. 3, 2012, pp. 339-345. doi:10.1016/j.elstat.2012.04.003

[14] A. Konrad and M. Graovac, "The Finite Element Modeling of Conductor and Floating Potential,” IEEE Transactions on Magnetics, Vol. 32, 1996, pp. 4329-4331. doi:10.1109/20.538859

[15] H. Zildzo, A. Muharemovic, I. Turkovic and H. Matoruga, "Numerical Calculation of Floating Potential for Large Earthing System,” 22nd Int. Symp. on Information, Communication and Automation Technologies, Bosnia, 2009, pp. 1-6.

[16] A. Castellani, A. Bondiou-Clergerie, P. Lalande, A. Bonamy and I. Gallimberti, "Laboratory Study of the Bi-leader Process from an Electrically Floating Conductor,” IEE Proceedings - Science, Measurement and Technology, Vol. 145, 1998, pp. 193-199.

doi:10.1049/ip-smt:19982011

[17] M. Abdel-Salam, M. T. El-Mohandes and H. El-Kishky, "Electric Field around Parallel DC and Multi-phase AC Transmission Lines,” IEEE Transactions on Electrical Insulation, No. 25, 1990, pp. 1145-1152.

[18] M. Trlep, A. Hamler, M. Jesenik, et al., "Electric Field Distribution under Transmission Lines Dependent on Ground Surface,” IEEE Transactions on Magnetics, 2009, No. 45, pp. 1748-1751.

[19] Y. Yang, J. Lu and Y. Lei, “A Calculation Method for the Hybrid Electric Field under UHVAC and UHVDC Transmission Lines in the Same Corridor," IEEE Transactions on Power Delivery, Vol. 25, No. 2, 2010, pp. 1146-1153.doi:10.1109/TPWRD.2009.2036359

[20] A. Z. E. Dein, M. A. A. Wahab, M. M. Hamada, et al., "The Effects of the Span Configurations and Conductor Sag on the Electric-field Distribution under Overhead Transmission Lines," IEEE Transactions on Power Delivery, No. 25, 2010, pp. 2891-2902.

doi:10.1109/TPWRD.2010.2051340

[21] K. Hameyer, R. Mertens and R. Belmans, "Numerical Methods to Evaluate the Electromagnetic Fields Below 
Overhead Transmission Lines and Their Measurement," Proceeding of First IEEE International Conference on Devices, Circuits and Systems, Caracas, Venezuela, 1995, pp. 32-36.

[22] J. Zhang, G. Zhang, X. Zhang, et al., "Simulation Experiment and Calculation of DC Electric Field Caused by DC Transmission Line at High Altitude Districts,” High Voltage Engineering, Vol. 35, No. 8, 2009, pp. 1970-1974.

[23] R. Amiri, H. Hadi and M. Marich, “The Influence of Sag in the Electric Field Calculation around High Voltage Overhead Transmission Lines," IEEE Conference on Electrical Insulation and Dielectric Phenomena. 2006, pp. 206-209.

[24] T. A. D. C. Society, IEEE Guide for Maintenance Methods on Energized Power Lines, 2009.

[25] P. Zhao, C. Deng and Y. Yuan, "Patrol of Transmission
Line with Helicopter," North China Electric Power, No. 10, 2002, pp. 1-3.

[26] J. S. Jung, J. W. Jung and S. Kim, "Transient Phenomena Analysis of Electric Shock Using ATPDraw," ICEE Conference on Progress, July. 2007.

[27] J. D. Tranen and G. L. Wilson, "Electrostatically Induced Voltages and Currents on Conducting Objects under EHV Transmission Lines," IEEE Tranactions on Power Apparently Systems, Vol. pas-90, No. 2, March/April, 1971.

[28] L. R. Delaplace and J. P. Reilly, "Electric and Magnetic Field Coupling from High Voltage ac Power Transmission Lines - classification of short - term effects on People,” IEEE Tranactions on Power Apparently Systems, Vol. pas-97, 1987, pp. 2243-2252.

[29] J. G. Anderson, “Transmission Line Reference Book 345 KV and above,” Electric Research Council and Electric Power Research Institute, Palo Alto, 1982. 